\title{
SER CRIANÇA? ÓTIMA PERGUNTA!
}

\section{- ECLEIDE CUNICO FURLANETTO}

https://orcid.org/0000-0002-1326-3075

Universidade Cidade de São Paulo

KARINA ALVES BIASOLI

https:/ /orcid.org.0000-0002-9222-3329

Universidade Cidade de São Paulo

RESUMO

O presente estudo se propôs ampliar a compreensão sobre os sentidos que as crianças atribuem à infância e à sua constituição como crianças. Ante inúmeras narrativas socialmente construídas em torno da infância e da criança, acreditamos ser necessário explorar aquelas produzidas pelas próprias crianças. Sob o aporte teórico da pesquisa (auto)biográfica em educação e da sociologia da infância, foram ouvidas catorze crianças com idades entre três e doze anos. Os dados foram produzidos a partir da realização de entrevistas narrativas. Considerando o período de isolamento social, devido à pandemia causada pelo Covid-19, os encontros presenciais foram substituídos por encontros virtuais, mediante a utilização de mensagens de áudio, vídeo ou texto, elaboradas pelas crianças. Os resultados indicaram três temáticas de análise: o caráter intrínseco que o brincar assume na constituição de suas subjetividades; a escola como espaço onde mais fortemente elas se percebem como crianças; e as relações de negociação que estabelecem com os adultos. Verificouse que ser criança implica para esse grupo processos de interação com os adultos que nem sempre se dão de forma dialógica, sobretudo, quando indicam as negociações que são estabelecidas sobre seus espaços e o brincar.

Palavras-chave: Pesquisa (auto)biográfica. Narrativas. Sociologia da infância. Crianças. Infância.

\section{ABSTRACT TO BE A CHILD? GREAT QUESTION!}

This study aimed to expand the understanding of the meanings that children attribute to childhood and its constitution as children. Before countless socially constructed narratives around childhood and children, we believe it is necessary to explore those produced by the children themselves. For this, the narratives of fourteen children, 
aged between three and twelve years, were heard. Under the theoretical support of (auto) biographical research in Education and the Sociology of Childhood, the data was produced from the realization of narrative interviews. Considering the period of social isolation, due to the pandemic caused by COVID-19, face-to-face meetings were replaced by virtual meetings, using audio, video or text messages, prepared by the children. The results indicated three themes of analysis: the intrinsic character that play assumes in the constitution of its subjectivities; the school as a space where they most strongly perceive themselves as children; and the negotiating relationships they establish with adults. It was found that being a child implies, for this group, processes of interaction with adults do not always take place in a dialogical way, especially when they indicate the negotiations that are established about their spaces and playing.

Keywords: (Auto)biographical research. Narratives. Sociology of childhood. Children. Childhood.

\section{¿SER UN NIÑO? ¡GRAN PREGUNTA!}

Este estudio tuvo como objetivo ampliar la comprensión de los significados que los niños atribuyen a la infancia y su constitución como niños. Ante innumerables narrativas socialmente construidas sobre la infancia y los niños, creemos que es necesario explorar las producidas por los propios niños. Para esto, se escucharon catorce niños, con edades comprendidas entre tres y doce años. Bajo el apoyo teórico de la investigación (auto) biográfica en Educación y Sociología de la Infancia, los datos se produjeron a partir de la realización de entrevistas narrativas. Considerando el período de aislamiento social, debido a la pandemia causada por COVID-19, las reuniones cara a cara fueron reemplazadas por reuniones virtuales, utilizando mensajes de audio, video o texto, preparados por los niños. Los resultados indicaron tres temas de análisis: el carácter intrínseco que el juego asume en la constitución de sus subjetividades; la escuela como un espacio donde se perciben más fuertemente como niños; y las relaciones de negociación que establecen con los adultos. Se descubrió que ser niño implica, para este grupo, que los procesos de interacción con los adultos no siempre tienen lugar de manera dialógica, especialmente cuando indican las negociaciones que se establecen sobre sus espacios y juegos.

Palabras clave: Investigación (auto)biográfica. Narrativas. Sociología de la infancia. Niño. Infancia. 


\section{Introdução}

Ser criança? Ótima pergunta! Essa é a única fase da nossa vida que passa muito rápido, se a gente for pensar, porque quando a gente é bebê a gente nunca se lembra quando tem 10 anos; $e$ quando a gente fica com 20 anos, a gente não lembra o que era com 10. Mas ser criança é jogar bola, é se divertir com o vizinho, é dar risada, é fazer uma loucura, sabe? (Miguel, 11 anos)

O título do artigo se inspira nas palavras de Miguel: "Ser criança? Ótima pergunta!". Os temas da infância e da criança vêm sendo explorados por inúmeros pesquisadores de áreas e correntes diversas. Eles se referem à criança das estatísticas, à criança generalizada, à criança idealizada e a outras mais, no entanto, apostamos que as crianças ainda têm algo a acrescentar, pois elas falam do lugar da criança encarnada que está na vida "viva" e é capaz de contar o que experimenta, pensa e sente.

Nesse sentido, assumimos uma perspectiva de investigação que situa a criança como sujeito capaz de refletir e construir sentidos sobre o que é ser criança. De tal forma, que suas narrativas se entrelaçassem a outras narrativas que procuram delimitar o conceito de criança e de infância, e sobre os sentidos que, historicamente, foram atribuídos à criança, à infância e aos espaços a ela destinados.

Nessa perspectiva de investigação com crianças, recorremos ao referencial teórico metodológico da pesquisa (auto)biográfica e, como instrumento de pesquisa, as narrativas da experiência vivida pela criança na escola, a fim de que os procedimentos utilizados fossem os mais adequados possiveis para atingir os objetivos propostos para esse estudo.

Cabe ressaltar que essa pesquisa se insere no contexto de investigações tecidas, coletivamente, por pesquisadores nacionais e internacionais que se disponibilizaram a escutar crianças a respeito de suas experiências'.

1 "Narrativas, educação, saúde: epistemologia e méto-
Feitas as considerações iniciais, apresentam-se as bases que estruturam o desafiante e proficuo percurso de compreender a criança. Para tecer esse caminho, optamos por circundar a temática da infância de modo a olhá-la de diferentes lugares: o da legislação que define a criança como sujeito de direito, o da tradição que sugere a presença do arquétipo da criança em diferentes culturas, o da ciência que busca compreendê-la a partir de estudos científicos e, sobretudo, incluímos as narrativas infantis que revelam o que as crianças pensam e sentem, a partir de suas experiências, sobre o que é ser criança.

\section{A legislação e a infância}

Inicialmente, optamos por pontuar os recentes investimentos, em termos legais, que têm atribuído à criança o status de sujeito de direitos, no sentido de evidenciar o seu lugar nas sociedades ocidentais. Movimento esse que, iniciado em 1919 com a criação do Comitê de Proteção da Infância, pela Sociedade das Nações Unidas, forma embrionária do que atualmente conhecemos por Organização das Nações Unidas (ONU), é retomado no ano de 1924, por meio da Declaração de Genebra, indicando a necessidade de assegurar os direitos à vida e à dignidade de crianças e adolescentes (GENEBRA, 1924).

Após essas primeiras iniciativas, outros documentos foram elaborados, ampliando não apenas o rol de direitos que deveriam ser assegurados a crianças e adolescentes, mas consolidando uma narrativa que situa a criança

dos da pesquisa (auto)biográfica com crianças" projeto de pesquisa financiado pelo Ministério da Ciência, Tecnologia e Inovações (MCTI) e Conselho Nacional de Desenvolvimento Científico e Tecnológico (CNPq) (Chamada no 06/2019, processo no 307063/2019-4), projeto "Narrativa, educação e saúde: crianças, família e professores entre o hospital e a escola", financiado pelo MICT-CNPq (Chamada no 28/2018, processo no 443695/2018-8), ambos coordenado por Maria da Conceição Passeggi. 
como sujeito e define as formas pelas quais sua vida deve ser regida, e que ensejou a elaboração do Estatuto da Criança e do Adolescente (BRASIL, 1990) assegurando prioridade absoluta da infância na oferta de políticas públicas; alterando as políticas de educação para a infância, norteadas pela Lei de Diretrizes e Bases da Educação (LDB) (BRASIL, 1996); permitindo chegar a um grau de sofisticação que inclui o direito ao brincar como parte essencial do seu desenvolvimento.

Embora a narrativa da criança como sujeito de direitos seja mais uma das possíveis narrativas sobre a infância e sobre o que é ser criança, sua estruturação parte de uma perspectiva universal que necessita ser manejada a partir das diferenças econômicas, sociais, culturais e geográficas que permeiam as diferentes infâncias. Mais do que isso, depende dos processos comunicacionais sociais mais amplos, para que possa ser reconhecida como legítima, uma vez que, segundo explicam os estudos de Marcová (2017) e Honneth (2009), o reconhecimento de um direito implica necessariamente processos dialógicos, de acolhimento e validação social de uma dada demanda, para que possa ser operacionalizado na esfera social e ultrapasse seus limites meramente formais. Dito isso, é importante resgatar outras narrativas construídas a respeito da criança.

\section{A criança na perspectiva das tradições culturais}

Antes mesmo do reconhecimento do lugar social da criança e da construção de um conceito de infância, observamos que inúmeras narrativas sobre crianças foram elaboradas, sobretudo, a partir da tradição cultural, posto que o nascimento de uma criança era tomado como um grande mistério e se colocava como algo a ser compreendido e significado culturalmente. Nesse sentido, a criança deu origem a símbolos importantes ainda presentes no imaginário de diferentes culturas, situadas em tempos e espaços diversos e pode ser considerada um arquétipo que povoa, entre outros, o inconsciente coletivo dos seres humanos (JUNG, 2000).

A realidade, como diz Morin (1997), inclui contraditoriamente o real e o simbólico, noções complementares e não antagônicas como se costuma pensar. Dessa forma, as produções míticas sobre a criança também se impõem culturalmente, assim como, as definições contidas nos manuais de psicologia sobre desenvolvimento humano e nos textos legais. Byington (2011) nos lembra que os mitos estão vivos, visto que esboçam padrões culturais que ainda inspiram trajetórias existenciais por meio da dimensão imaginária e pela memória coletiva, cujos principais exemplos se encontram nos mitos e nos contos de fada.

$\mathrm{Na}$ mitologia grega, por exemplo, cabe salientar que deuses e heróis têm suas histórias relatadas desde o início de suas vidas, como é o caso de Hércules e Hermes, filhos ilegítimos de Zeus. Hércules, aos oito meses, foi obrigado a se proteger de Hera, esposa ciumenta de seu pai, que enviou duas enormes serpentes para exterminá-lo, depois de matá-las, ele assume o seu destino heroico. Hermes, ainda bebê, teceu a artimanha de roubar o gado de seu irmão Apolo para ser levado a presença do pai. Zeus, cativado pela esperteza do filho o perdoou, sob a condição de que ele não mentiria mais. Ele prometeu dizer a verdade, mas não toda a verdade, e conseguiu assim ser admitido no Olimpo. A mitologia refuta, como se observa na trajetória de Hércules e Hermes, uma visão idealizada de fragilidade envolvendo a criança no início da vida, sinalizando que desde cedo são postas à frente de situações que exigem uma certa dose de heroísmo para sobreviverem.

Os contos de fadas, embora originalmente destinados aos adultos e transmitidos pela 
tradição oral, permaneceram sendo contados de geração em geração por abordarem situações típicas enfrentadas pelos humanos, tornando-se, dessa forma, emblemas de processos psíquicos e de suas possiveis elaborações (PIERI, 2002). As crianças sentem por eles uma enorme atração, por oferecem possibilidades de superação de desafios em busca de perspectivas de crescimento que as auxiliem nas suas próprias buscas (VON FRANZ, 1985). Assim como na mitologia, nos contos de fadas, as crianças têm um papel preponderante ao serem confrontadas com acontecimentos que demandam superação. É o que ocorre com os personagens tão conhecidos como os de João e Maria; Chapeuzinho Vermelho; Branca de Neve; o Patinho Feio e Dumbo, todos vivem situações de abandono, perseguição, desamparo, medo e ameaças.

Para Jung (2000), a criança se identifica com os personagens dos contos de fadas, justamente, porque eles reafirmam a importância do desligamento da origem que se configura como condição necessária para a autonomia e o crescimento individual. Assim, tanto as narrativas mitológicas quanto as populares realçam, por um lado, a imagem da criança vulnerável e indefesa e, por outro, sua força e capacidade para ultrapassar obstáculos e vencer inimigos, para elas "poderosíssimos", "assustadores", "enganadores". Para Chevalier e Gheerbrant (1998), que se dedicam ao estudo dos símbolos, a infância é vista como símbolo da inocência, da simplicidade natural e é representada em diversas tradições como o retorno ao princípio.

Na cultura asiática, o Taoísmo considera a criança como um ser espontâneo, sem pensamentos dissimulados, possuidora de naturalidade a ser preservada. No Hinduísmo, o estado de infância é denominado Bayla e é percebido como o estado anterior à obtenção do conhecimento. Existe um saber na criança que preci- sa ser conservado para que se possa adquirir o verdadeiro conhecimento.

Nietzsche (1979) retoma o sentido que a criança assume nas tradições, por meio de aforismos, e descreve as transformações pelas quais deve passar o espírito. Inicialmente, o espírito toma a forma de um a camelo: sólido, sadio e pesado, que se curva para carregar em seu dorso o que ali for colocado. Em seguida, ocorre uma segunda transformação, o espírito, no deserto isolado, se apresenta como um leão, que conquista a liberdade por meio da luta e da vitória sobre seus inimigos. Então, surge a terceira transformação, na qual o espírito toma a forma de uma criança, que representa o novo, a força que desperta com sabedoria, a inocência em busca do recomeço, o espírito não quer mais conquistar o mundo, mas ir em busca de seu mundo.

Do ponto de vista simbólico, a criança representa, portanto, a inocência e a fragilidade, como também a força capaz de travar grandes lutas, enfrentar desafios e sair vencedora. Ela representa, concomitantemente, o começo, o recomeço e o fim. Algo dela precisa ser preservado durante a maturidade para que o adulto preserve sua criatividade e continue aberto ao porvir que, na perspectiva das tradições, não se reduz a um processo evolutivo comprometido com a superação de etapas anteriores, mas uma rota sinuosa, permeada por grandes lutas, idas e vindas, perdas e ganhos e por constantes recomeços que podem se iniciar desde a mais tenra idade.

\section{A criança na perspectiva do conhecimento científico}

$\mathrm{Na}$ perspectiva do pensamento científico, outras narrativas sobre ser criança e sobre a infância foram delineadas por diferentes áreas do conhecimento, destaque pode ser dado: à psicologia, à pedagogia, à sociologia, à antropo- 
logia, à saúde, à filosofia e ao Direito. Essa pluralidade de narrativas pode ser vislumbrada na medida em que adjetivamos o termo "criança". Temos a criança inteligente, a criança em situação de vulnerabilidade social, a criança doente, a criança sujeito de direitos e muitas outras. $E$, para cada uma dessas crianças são definidos espaços, ações, políticas, condutas, práticas pedagógicas e de cuidados, direitos, conformando infâncias completamente distintas.

O investimento em tais áreas e análises permitem observar que não há, portanto, uma criança universal, razão pela qual, concordamos com a perspectiva de Freitas (2016) que situa a criança como o sujeito que vive e age, dentro desse espaço/tempo definido, cultural e historicamente, como infância.

Essa multiplicidade de narrativas nos levou a pensar na existência de uma infância definida não apenas pelo decurso do tempo situado entre o nascimento e o início da fase adulta, mas como resultado de construções culturais e históricas que cristalizaram diferentes representações sobre esse período inicial da vida humana e que, portanto, nos indicavam a existência de múltiplas infâncias já do ponto de vista conceitual, a partir das diferentes áreas de conhecimento, implicando construções distintas de suas subjetividades, segundo apontam os estudos de Freitas (2016) e de Andrade (2015).

Conforme explica Andrade (2015, p. 16), a infância, considerada a partir de uma perspectiva plural, se dá como "construção sociocultural cujos significados regulam práticas sociais e educacionais frente às quais adultos e crianças interagem, incorporando-as, negando-as e mesmo reinterpretando-as".

Assumir uma postura epistemológica que considera a infância como produto sociocultural implica também uma análise sobre os espaços/tempos destinados a essas crianças, contemplando uma frente de investigação também plural, de tal modo que olhar para esses espaços ou sua ausência nos permitisse compreender os condicionantes que, dentre inúmeras variáveis, privilegiam um determinado modo de organização das atividades infantis em detrimento de outros tantos possiveis.

Conforme explica Andrade (2015), todo espaço se constitui como artefato cultural, marcado por reguladores sociais que, a partir da imagem que se tem construída sobre a infância e sobre o que é ser criança, são objetivados na forma como são organizados. Objetivações essas que poderiam ser identificadas, no caso do ambiente escolar, pelo modo como os mobiliários são distribuídos nas salas, quais são os sistemas de segurança que envolvem o trânsito das crianças por esses espaços, quais são as atividades e horários definidos para seu uso; quais regras permeiam as experiências nesses locais, qual o grau de participação oferecido às crianças na construção de tais arranjos, quais são as estratégias de negociação que empreendem com os adultos e com a própria rotina, e quais são as relações que estabelecem com esses espaços.

Definem-se, dessa forma, os contornos de atuação, as relações entre adultos e crianças, numa perspectiva que pode tanto oferecer espaços de protagonismo quanto silenciar suas vozes, produzindo subjetividades e narrativas específicas sobre o que é ser criança nos diferentes tempos e espaços em que se encontram inseridas, de tal modo que personificam-se, justamente por decorrerem de processos simbólicos que se materializam em arranjos institucionais que definem formas de agir, orientam as dinâmicas da vida ativa, constroem visões de mundo e expressam identidades de atores sociais.

É no interior desses processos simbólicos e narrativos que se estruturam as experiências, de criança e adultos sobre a vida e sobre as formas de como vivê-la, posto que formam 
uma comunidade específica e oferecem, de forma dialógica, o "elo entre o sujeito singular e o mundo social" (JOVCHELOVITCH, 2011, p. 127), resultando, desses encontros, um repertório comum de saberes que asseguram a experiência de pertença a dado grupo e também os meios de exclusão daqueles que destoam das narrativas convencionadas. As narrativas individuais entrelaçadas às narrativas comunitárias, definem tanto o outro quanto o eu, delimitam fronteiras marcadas por relações de poder e dominação que podem resultar em maior ou menor adesão, conforme explica Jovchelovitch (2011, p. 137)

Narrativas individuais e narrativas coletivas são entrelaçadas de tal modo que, quando a história de uma vida individual é contada, ela contém a história, os acontecimentos, as formas culturais e as maneiras de se comportar de toda uma comunidade [...] permitem a sujeitos individuais reconhecer neles o seu poder, com eles se identificar ou deles se distanciar, apoiá - los ou apaixonadamente rejeitar o que está em jogo.

Sobre esses processos simbólicos que envolvem a organização dos espaços, é possivel olhar também para espaços sociais mais amplos e refletir sobre quais imagens de infância e de criança orientam, por exemplo, as políticas urbanísticas de uma cidade. Quais espaços lhes são destinados e com quais finalidades? Quais narrativas decorrem desses espaços? Dessas narrativas, decorrem, conforme explicam Jovchelovitch (2011) e Marková (2017), tanto os processos dialógicos que consideram a perspectiva do outro como legítima, como processos não dialógicos que se caracterizam, essencialmente, pela falta de seu reconhecimento, como por exemplo, quando observamos espaços sociais em que as crianças participam mais ativamente e são acolhidas a partir da consideração de suas necessidades, e outros, menos sensiveis a tal escuta.
No campo da sociologia, o precursor dos estudos sobre infância Ariès (1981) relata que a ideia de infância, tal como conhecemos é um produto da modernidade, dada a ausência de uma clara distinção entre as crianças e os adultos, posto que nas culturas medievais, crianças e adultos se misturavam nas diferentes atividades sociais o que encurtava, por assim dizer, o tempo da infância. Mais do que simplesmente interagir com os adultos, as crianças assumiam um papel fundamental, integrando-se como força de trabalho, a partir da qual se assegurava o sustento de toda a comunidade (QVORTRUP, 1999, 2011; 2014) e se conformava, tacitamente, um pacto de cuidados reciprocos entre os mais velhos e os mais jovens. Aspectos esses que se distanciavam de qualquer possibilidade de distinção entre essas etapas geracionais e asseguravam um lugar de visibilidade às crianças.

Contudo, segundo explica Qvortrup (1999), as alterações dos modos de produção, iniciadas já no período pré-industrial, passaram a delinear o surgimento do que hoje entendemos por infância. Na medida em que se ampliava o modelo de produção industrial, as riquezas que até então eram produzidas e partiIhadas coletivamente foram substituídas pelos pagamentos de salários de forma individual. Tal alteração não apenas destituiu as crianças de seu papel produtivo, como as impeliu a situações muito precárias de vida, posto que os salários pagos não correspondiam mais à proporção de seu trabalho, uma vez que o trabalho que desenvolviam no campo foi substituído pelo trabalho escolar, postergados os frutos, para um tempo futuro (QVORTRUP, 1999, 2011, 2014).

De forma contraditória, na mesma medida em que as crianças foram retiradas das esferas públicas e sociais, maiores foram os investimentos em estudos e legislações que legitimaram a institucionalização da infância, inclusi- 
ve sob o argumento de uma maior proteção. Embora não se negue ser necessário proteger as crianças de toda a forma de abuso ou violência, o que se verificou foi a construção de espaços que resultaram na legitimação de sua segregação social (QVORTRUP, 1999; 2011; 2014).

Teve papel preponderante nessa institucionalização a elaboração de um conjunto de saberes que definiram a "criança normal" e veicularam prescrições assentadas na medicina, na pedagogia, na psicologia, sendo que esta última estruturou a psicologia do desenvolvimento, colaborando para a construção de uma representação de criança como um ser em processo de evolução e maturação. Constituíram-se, desse modo, os meios pelos quais se deu a administração simbólica da infância, sustentada pela definição de regras e normas que, de uma certa forma, codificaram e regularam os espaços destinados às crianças, a suas próprias vidas e reforçaram a construção de um novo ofício, agora, o de aluno.

Na perspectiva de Sarmento (2011, p. 587), “Com a escola, a infância foi instituída como categoria social dos cidadãos futuros, em estado de preparação para a vida social plena. Na verdade, é o aluno - mais do que a criança - de quem a escola se ocupa". Dessa forma, a criança desaparece enquanto um ser singular para dar espaço a alguém que aprende segundo as prescrições dos adultos. Conforme Skliar (2014), a escola provoca uma interrupção da infância. Cabe ao corpo entrar em uma nova ordem. A ficção que permite a liberdade e a abertura deve ser enclausurada. 0 olhar que se volta para todos os lados, traduzido em atenção dispersa, deve se fixar. A linguagem encarnada deve ser substituída por uma língua única desabitada. E a escola, como foi idealizada, não está voltada para a criança, e sim para a transmissão de aspectos da cultura considerados importantes para transformar a criança em aluno e, por sua vez, o aluno em adulto. A criança passa a ser vista como um ser incompleto situado num tempo de passagem para um estado a ser alcançado.

No conjunto de narrativas socialmente tecidas sobre a infância, as crianças se constituem como sujeitos singulares por meio de um processo de bricolagem que congrega, a um só tempo, narrativas pautadas nas tradições, nos documentos legais, na produção científica, entre outras. Tecidas as considerações sobre a temática, privilegiamos uma análise das narrativas das próprias crianças sobre os sentidos que atribuem à infância e ao ser criança.

\section{Ao encontro das crianças}

É importante destacar que, mais recentemente, a sociologia tem oferecido novas perspectivas de compreensão da infância e de suas produções culturais (CORSARO, 2011) que contradizem teorias anteriores que reduziam a inclusão cultural das crianças a processos de adaptação, fruto da internalização de conhecimentos e habilidades dos adultos. Por sua vez, afirmam que a inserção das crianças na cultura vai além da adaptação, compreende apropriação, reinvenção e negociação que ocorrem, sobretudo, por meio da troca com os adultos e entre pares. Ao atribuírem sentidos sobre o que lhes é dado, por meio de trocas, as crianças produzem suas próprias culturas, implicando modos de ver e agir que até mesmo confrontam o que thes é apresentado. Dessa forma, ocorre um intercâmbio entre as culturas adultas que disponibilizam um conjunto compartilhado de expectativas e produções simbólicas e as culturas infantis que estabelecem novos significados ao acolher ou refutar o que lhes foi apresentado. Cabe salientar que aspectos das culturas infantis podem ser acessados, mediante os modos de agir e de narrar o vivido pelas crianças (PASSEGGI et al 2014), o que justifica nossa escolha por ouvi-las, de 
maneira a analisar os sentidos que atribuem às suas vivências infantis.

Os dados da pesquisa foram coletados durante o mês de abril de 2020, ocasião em que a população da cidade de São Paulo se encontrava submetida às medidas de isolamento social, em virtude da pandemia provocada pelo Covid-19. Ante a impossibilidade de encontros presenciais e atendendo aos princípios éticos e metodológicos que envolvem a pesquisa com crianças (KRAMER, 2002; DEMARTINI, 2002; PASSEGGI et al., 2014; PASSEGGI, NASCIMENTO, RODRIGUES, 2018), após um contato prévio com famílias com crianças, definimos os seguintes critérios para a seleção dos participantes: idade até 12 anos; e perfis socioeconômicos diversificados que pudessem, ao menos em parte, representar a diversidade existente na cidade de São Paulo. Desse modo, após a autorização dos responsáveis legais e anuência das crianças para participar da pesquisa, o grupo foi composto por sete meninas e sete meninos, com idades entre três e doze anos, estudantes de escolas públicas e privadas.

A produção dos dados foi orientada com base na entrevista narrativa, descrita por Jovchelovitch e Bauer (2002). Como estávamos impedidas de ter contato pessoal, as entrevistas foram realizadas, em sua maioria, por meio do aplicativo WhatsApp, mediante o uso de mensagens de áudio, vídeo ou mensagens escritas, conforme a escolha das próprias crianças, considerando as formas que lhes fossem mais confortáveis. As entrevistas foram registradas pelas pesquisadoras e, posteriormente, transcritas. Os encontros virtuais foram desenvolvidos a partir de um protocolo comum estruturado em três momentos: a. apresentação da entrevistadora, da criança e dos objetivos da pesquisa; b. momento da narrativa da criança; e c. fechamento.

Durante o primeiro momento, foram apresentados os motivos da conversa, tendo como mote o fato de que as pesquisadoras também tinham algumas tarefas escolares a serem realizadas durante o período de isolamento social e, dentre elas, uma consistia em entrevistar crianças para saber o que elas tinham a dizer sobre o que é ser criança. Para as crianças menores, foi utilizado um dispositivo de mediação que consistiu em contar uma história sobre um ser de outro planeta que, chegando à terra, ficou curioso para saber o que era uma criança e que, por essa razão, gostaria de ouvi -las (PASSEGGI et al, 2014).

No segundo momento, o da narrativa da criança, foram oferecidas as possibilidades de envio de mensagens de vídeo ou áudio, e também, mensagens escritas, conforme se sentissem mais confortáveis. Dentre as opções oferecidas, verificamos que as crianças revelaram maior preferência por mensagens de vídeo e áudio, contando apenas com uma mensagem de texto. Após o envio das mensagens, foi realizado o terceiro momento, o de fechamento, apoiado em conversas informais e de agradecimentos pela ajuda prestada, e também sobre como cada uma havia se sentido ao relatar suas percepções sobre ser criança.

Após a transcrição e leitura do material coletado, as narrativas apresentadas foram tomadas em sua totalidade, formando um único corpus, tendo em vista que, embora compostas por palavras e frases curtas, atendiam ao objetivo da pesquisa biográfica de explorar a gênese e o devir dos indivíduos no seio do espaço social (DELORY-MOMBERGER, 2012), e revelavam, por meio da história de um instante, de uma hora, de um dia, como significavam suas experiências e suas existências, sem perder de vista o tempo biográfico situado na origem de uma percepção e o processo dialógico, mediante o qual, se dá a elaboração peculiar dos espaços de uma vida social.

Essa possibilidade do trabalho com narrativas, envolvendo diferentes idades, nos permi- 
tiu contemplar o papel que a linguagem assume nos processos de articulação entre o social e o individual, o público e o privado, o singular e o plural. A análise do material coletado foi orientada por um desejo de assegurar a fidelidade da voz das crianças, buscando identificar as temáticas por elas abordadas, de modo a depreender uma compreensão do que apresentavam sobre o ser criança, percorrendo os passos de análise já delineados em pesquisa anterior por Passeggi e demais autores (2014) e Passeggi, Nascimento e Rodrigues (2018).

\section{O que contam as crianças sobre ser criança?}

Embora tenhamos percorrido diferentes narrativas construídas em torno da infância e do que significa ser criança, ao analisarmos o material produzido o que nos saltou aos olhos, foi que as crianças gostam de ser crianças e talvez isso se desse em função da existência de um consenso entre as diferentes falas, o que não se alterava em relação à idade, ao sexo, tampouco em relação ao nível socioeconômico.

Outro aspecto dizia respeito aos espaços sinalizados como pertencentes à criança. Embora todas estivessem em período de isolamento e afastadas dos espaços escolares, verificou-se que dentre tantas possibilidades de espaços a serem indicados, a escola se mostrou preponderante. Uma apropriação dos códigos sociais também se evidenciou na medida em que narravam situações envolvendo interdições e permissões que regulam o seu agir. As relações estabelecidas entre seus pares e com os adultos, também foram indicadas, ora para sinalizar suas limitações enquanto crianças, ora para apresentar as possibilidades de crescimento e de aprendizagem que tais trocas lhes proporcionavam. Os resultados atenderam à possibilidade dessas crianças se voltarem sobre si mesmas e sobre as representa- ções que possuíam de si, que seguem apresentadas por meio da delimitação de quatro eixos de análise.

\section{O brincar e a criança}

Dentre as temáticas que surgiram a partir das narrativas das crianças, o brincar configurouse, de forma unânime, como característica constitutiva do que para elas, significava ser criança.

Mas, ser criança é jogar bola, é se divertir com o vizinho, é dar risada, é fazer uma loucura, sabe? (Miguel, 11 anos).

Para mim, é brincar, brincar de boneca, de vôlei, brincar de um montão de coisas. E também brincar de pecinha que também é muito legal. $E$ brincar de Barbie também é legal. Só isso (Victoria, 6 anos).

É se divertir, é brincar, é estudar, é dormir... só (Manuela, 9 anos).

A ideia que se tem atualmente sobre o papel do brincar para o desenvolvimento humano é bastante recente e resulta de estudos que foram empreendidos a partir do século XIX que permitem falar não apenas do homo sapiens, marcado pela lógica e pela cognição, mas também do homo ludens (SANTOS, 2011), constituído corporalmente por meio de suas experiências e pela liberdade de criar, junto com seus pares, condições, instrumentos e estratégias simbólicas para se divertir e aprender, superando a dicotomia, até então existente, entre o trabalhar e o brincar, entre a produção e o ócio (KISHIMOTO, 2011a).

É importante salientar que as falas das crianças expressam que brincar é, sem dúvida, o espaço para a criação no qual se sentem livres para inventar mundos do "faz de conta", transitar no tempo e contar com os pares para viver suas aventuras. Para Winnicott (1975), existe uma relação intrínseca entre brincar e criar, é por meio da apercepção criativa que 
os indivíduos sentem que vale a pena viver. As crianças relutam em se submeter às normas ou hábitos institucionais, impostos pela escola ou pela família, e aos ditames reconhecidos como algo a que devem se ajustar. Para Winnicott (1975, p. 95), “A submissão traz consigo um sentido de inutilidade e está associada à ideia de que nada importa e de que não vale a pena viver a vida". Aqueles que provam viver de modo criativo, ao se distanciar dessa experiência, resistem e lutam de diferentes maneiras para retomar sua liberdade de criar. A tradição revisitada anteriormente foi capaz de captar a importância de manter viva a criança em cada um dos adultos, pois cabe a ela nutrir a capacidade criativa que atribui sentido à vida.

Numa perspectiva que resgata o caráter sociocultural do brincar, encontramos em Brougère (2001) e Kishimoto (2011a; 2011b) elementos que reforçam o seu papel mediador nos processos de apropriação, interpretação e inovação que a criança empreende frente a um contexto cultural já existente. Assim, encontramos, nas falas das crianças, o brincar como elemento constituinte de suas subjetividades. Situadas temporal e espacialmente, indicaram os meios pelos quais se apropriam de uma dada cultura, se inserem em seus grupos de pertença, como também escapam dos papéis sociais que thes são imputados e selecionam os instrumentos disponiveis para tal atividade.

Criança é uma pessoa bem agitada que quer sempre brincar com outras crianças (Ricardo, 12 anos).

As crianças brincam, tomam sorvete e gostam de Nutella (Luiza, 5 anos).

É legal, pode brincar, pode jogar (Thiago, 8 anos).

Brincar, pintar e fazer essas coisas (Lucas, 3 anos).

Embora sinalizassem o brincar como parte indissociável do sentido atribuído ao ser crian- ça, percebemos que havia uma tensão entre a produtividade, representada pelo trabalho e ócio criativo, relacionado com o brincar na medida em que estabeleciam uma distinção entre suas vidas e a vida dos adultos. Elas anteveem um tempo em que o brincar será substituído pelo trabalhar, perspectivando, desse modo, que perderão algo que thes é muito caro. As crianças parecem ter uma percepção de que o trabalho é algo penoso que um dia terão que realizar. A infância será interrompida e uma travessia deverá ser feita.

É legal ser criança, a vida é mais fácil para as crianças do que para que os adultos. Eles têm que trabalhar para sustentar os filhos (Ricardo, 12 anos).

É legal ser criança [...] não precisa trabalhar (Helena, 7 anos).

Ser criança, para mim, é brincar, se divertir e se preparar para o futuro (Carolina, 9 anos).

A respeito da brincadeira infantil, Kishimoto (2011b) esclarece que, na visão dos adultos, o brincar acaba, muitas vezes, sendo considerado como atividade destituída de seriedade e contraposta à rigidez do trabalho, justamente por ser marcada pelo riso, pela diversão e pelo humor. No entanto, esse seria um equívoco, na medida em que a criança, quando brinca, o faz de modo muito competente e entrega-se com seriedade ao que está fazendo, sem culpa e sem sensação de estar perdendo.

No conjunto das análises, pudemos observar que apenas uma criança, de três anos de idade, conseguiu aproximar o brincar do aprender.

Também a gente pode brincar, brincar de cachorro, brincar de escovar o dente, brincar de mamãe e filhinha com a minha mamãe, brincar de cabelereira [...] (Giulia, 3 anos).

A fala de Giulia denota uma capacidade que a criança possui de integrar a brincadeira nas situações de aprendizagem que 
permeiam seu cotidiano, o que lhe permite tomar o real, selecionar determinados conteúdos, apropriar-se das regras que orientam diferentes comportamentos sociais e, a partir de experiências, atribuir novos sentidos ao vivido. Essa aproximação entre brincar e o aprender vai se esvaindo na medida que as crianças crescem. Brincar e aprender vão se tornando opostos, e a escola contribui para que isso aconteça, fomentando uma cultura adultocêntrica que não valida o brincar como parte constitutiva das aprendizagens (FURLANETTO, HERRERA e MEDEIROS, 2018).

\section{A escola e a criança}

Como vimos anteriormente, a escola, segundo Sarmento (2011), teve um papel preponderante na institucionalização da infância. Muitos autores discutem as contribuições da escola na estruturação da contemporaneidade, (PÉREZ GÓMEZ, 2004; FOUREZ, 2008; CHARLOT, 2013; MASSCHELEIN; SIMONS, 2013). Esses autores assumem posições que, frente ao papel controverso desempenhado pelas escolas, descortinam suas luzes e sombras e discutem suas inadequações frente às sociedades contemporâneas e às formas como as crianças são inseridas socialmente.

As crianças, à medida que vão crescendo, tendem a incorporar aspectos da cultura adulta que vê o brincar como algo a ser superado para que se possa assumir a seriedade da vida dos adultos que inclui o trabalho. Conforme explica Sarmento (2011), ao ingressar na escola, a criança se submete aquilo que denominou de ofício do aluno, regido por práticas que visam à regulação de comportamentos, exercendo um controle não apenas sobre o corpo e sua expressividade comunicativa, mas construindo uma narrativa de que para aprender os conteúdos escolares é necessário deixar de brincar.
Ela [a criança] gosta de brincar e não gosta de fazer lição (Pedro, 9 anos).

Não gosto das aulas, tem que ficar quieta (Helena, 7 anos).

Eu mudei de escola, eu não gostava da outra, então pedi para meus pais para mudar. As professoras da escola que eu estou são legais (João, 10 anos).

A desconexão entre brincar e os processos de aprendizagem sinalizados por algumas crianças adquiriu relevância, na medida em que, dentre todos os espaços possiveis que poderiam ter sido apresentados em suas narrativas, o único a ser indicado foi o espaço escolar. Conforme explica Barbosa (2007), a escola é a única instituição da modernidade destinada, de forma compulsória, a crianças e jovens e que possui um público sempre presente, diferentemente de outras instituições sociais que, como museus, parques, bibliotecas, precisam desenvolver estratégias de formação de público. Considerar, analisar e integrar outras modalidades socializadoras no processo educativo poderia oferecer elementos mais dialógicos entre as culturas infantis e a cultura escolar.

A representação desse espaço específico, confirmando os resultados dos estudos desenvolvidos por Andrade (2015), Jodelet (2002) e Jovchelovitch (2011), mostrou-se profundamente marcada por estruturas simbólicas que definiam formas de agir que silenciavam o brincar, limitando-o ao espaço/tempo do recreio e desconsiderando o caráter intrínseco que o brincar assume no sentido que essas crianças atribuíram ao ser criança. 0 panorama envolvendo a escola e o brincar se configurou de forma pouco dialógica, de modo que, para as próprias crianças, o brincar passou a se constituir como atividade marginal dentro do ambiente escolar, desconectada simbolicamente dos seus processos de aprendizagem. 
Vão para a escola, mas não gostam de ir para a escola, gostam do lanchinho da escola e das amigas e da aula de música (Luiza, 5 anos).

Criança vai para a escola, lá tem amigos, no recreio dá para brincar com os amigos, mas não gosto das aulas (Helena, 7 anos).

Estou feliz. Se alguma criança não estiver feliz na escola e quiser mudar, diga para vir para a minha (João, 10 anos).

[...], mas não gostam muito de ir para a escola (Pedro, 9 anos).

A gente tem que ir para a escola para aprender várias coisas (Beatriz, 10 anos).

A maioria acha que a escola é chata. Tem outra parte que gosta de estudar e outra parte gosta de ir para a escola para encontrar com os amigos (Ricardo, 12 anos).

Embora algumas falas indicassem estruturas rigidamente construídas no espaço escolar, João, Beatriz e Pedro nos oferecem pistas de que a negociação estabelecida entre adultos e crianças pode resultar em melhores aprendizagens, maior sentimento de pertença, garantia de bem-estar, construção da autoconfiança, do autorrespeito e da autoestima, na perspectiva dialógica proposta por Honneth (2015). O desafio que se coloca, segundo Barbosa (2007), é o de repensar a socialização das crianças a partir do entrecruzamento das culturas escolares, consideradas legítimas, e suas relações com as culturas familiares e infantis consideradas, muitas vezes, como ilegítimas pela escola.

O recreio é mais longo. Estou indo bem nessa escola, tenho mais amigos [...] (João, 10 anos).

Eu gosto da escola, porque têm vários amigos para brincar (Beatriz, 10 anos).

Elas gostam de brincar com os amigos, quando estão na escola [...] (Pedro, 9 anos).

\section{Os códigos sociais e a criança}

Outro aspecto que se destacou dizia respeito a um entendimento que já possuíam sobre os códigos que indicavam quais de suas ações eram ou não consideradas socialmente aceitas como brincadeira ou como transgressão. Essa observação surgiu, na medida em que as crianças utilizavam as palavras "pode" e "não pode", sinalizando a existência de uma relação entre direitos e deveres.

Criança é uma pessoa legal que pode fazer o que quiser, pode jogar bola, mas sem se machucar [...]. Mas criança também não pode fazer algumas coisas, tipo beber álcool, não pode matar aula, não pode trabalhar, antigamente podia, agora não pode mais, não pode pular de lugar alto. Criança não tem dinheiro, não pode namorar, mas agora na minha escola nova pode (João, 10 anos).

Às vezes faz coisas erradas, como jogar bola na sala e quebrar o vaso (Pedro, 9 anos).

É legal, pode brincar, pode jogar. Pode fazer o que quiser, menos... não sair na rua (Thiago, 8 anos).

É legal ser criança, pode correr, brincar com outra criança [...]. Pode assistir canal para criança. Pode andar de patinete (Helena 7 anos).

Ser criança, para mim, é não pensar no que pode vir no futuro e sim no que está acontecendo quando você é criança... quando sua mãe tenta ficar te ensinando uma matéria... isso é ser criança (Miguel, 11 anos).

Embora tenham assinalado um conhecimento sobre permissões e interdições, direitos e deveres, numa perspectiva que as coloca como sujeitos de direitos, na medida em que se autodefinem como crianças, o que se destaca é um atravessamento da cultura adulta, numa espécie de classificação "café com leite", na qual participam do jogo, mas não são efetivamente levadas a sério. Revelaram, de forma até contraditória, a presença de uma crença que as compreende como "menores" e, por essa razão, precisariam ser tuteladas e normatizadas, para futuramente transformarem- 
se em adultos adaptados (PASSOS, 2007), na medida em que adjetivavam a palavra criança, com termos que, nem sempre, convergiam para uma ideia de criança potente.

Criança é pequena e daí vai crescendo e vira adulto (Beatriz, 10 anos).

Criança é uma pessoa bem agitada [...]. Ela é divertida, não tem muita noção do mundo (Ricardo, 12 anos).

Bem, uma criança é uma pessoa baixinha (Pedro, 9 anos).

Ser criança é uma coisa muito louca e engraçada [...]. Tem vários tipos de crianças (Miguel, 11 anos).

Conforme pudemos observar, as narrativas produzidas pelas crianças apontam uma pluralidade de sentidos ao ser criança que corroboram os estudos de Freitas (2016) e colocam em xeque as propostas que defendem uma infância e uma cultura adulta única.

Mais ainda, considerando que a experiência socializadora acontece de forma cada vez mais precoce fora do vínculo familiar, poderíamos pensar o processo de socialização de forma mais ampla também em relação à metáfora do espelho, proposta por Winnicott (1975) que, na relação entre a mãe e o bebê, há uma antecipação do lugar desse filho, e investigar se tais espaços ainda correspondem aos processos de socialização secundária ou se situam como espaços de socialização primária, abertos ao reconhecimento e ao acolhimento de suas singularidades. Conforme explica Passos (2007, p. 127),

A relação eu-outro é como um jogo com regras, leis e movimentos que vão sendo metamorfoseados ao longo da vida. Dele ninguém escapa. Pode-se, entretanto, reconstituí-lo, negociando suas imposições e encontrando saídas para os conflitos que lhes são implícitos. Essa saída revela a capacidade do sujeito de conhecer a si mesmo por meio do reconhecimento do outro, fundamento indispensável à socialização.

\section{Os pais, os amigos e a criança}

As crianças dão importância aos seus companheiros. Criança logo chama outra criança de "amigo(a)", palavra impregnada de querer bem e confiança, o que leva a crer que elas se sentem parte de uma comunidade que se configura de forma diferente da dos adultos e se caracteriza pela espontaneidade, por se divertir, por correr, enfim, compartilhar jogos e brincadeiras. Se as crianças gostam de jogar e brincar sozinhas, fazer isso com os amigos thes parece ser bem mais interessante. São interativas, elas buscam companhia de quem as cercam, mas sobretudo de outras crianças. Elas partilham, disputam, negociam, criam estratégias, mas, principalmente, aprendem umas com as outras ao coexistirem.

Na perspectiva de Corsaro (2011) e Sarmento (2004), as crianças estabelecem suas próprias culturas permeadas por valores, rotinas e artefatos que lhes são caros. "A convivência com os seus pares, através da realização de actividades e rotinas, permite-lhes exorcizar medos, representar fantasias e cenas do quotidiano, que assim funcionam como terapias para lidar com experiências negativas" (SARMENTO, 2004, p. 9). O brincar se desdobra em novos sentidos ao se mostrar como possibilidade de curar feridas deixadas por experiências que marcam e que necessitam ser elaboradas.

Dessa forma, os espaços a elas destinados tornam-se importantes, quando neles encontram seus companheiros. Como explicitam nas narrativas, elas vão para escola para encontrar os amigos e não é nas salas de aula que isso se torna possivel, podem estar com eles no recreio e nas aulas que oferecem mais liberdade para criar.

Os pais, presentes nas narrativas das crianças, se constituem como elementos que proporcionam proteção e acolhimento. Para Winnicott (2011), as crianças precisam de seguran- 
ça, mas cabe salientar que esse sentimento se constitui como um ponto de equilíbrio entre a superproteção e o abandono, nessa perspectiva, ela não pode vir em excesso, como também não deve faltar. Isso implica reconhecer as atitudes desafiadoras de seus filhos, as estratégias que eles utilizam para burlar as normas estabelecidas, não como ameaças pessoais, porém como maneiras de preservar sua autonomia. Por meio de suas experiências culturais, os pais podem encontrar meios de proporcionar a segurança necessária, mesmo frente às inseguranças manifestadas pela vida. É importante que a criança possa crer que exista algo que seja confiável, durável e capaz de se restaurar, e que, apesar de ter sofrido avarias, a família pode exercer esse papel.

Quando elas ficam muito tristes, elas choram, choram para que os pais vejam que elas estão tristes. Elas gostam dos pais, porque eles são a origem delas e se elas se perderem dos pais elas choram (Augusto, 8 anos).

Elas se importam muito com os pais, mas às vezes eles brigam sem motivos! (Pedro, 9 anos).

A gente gosta de ficar abraçado com os pais $e$ de assistir filmes (Beatriz, 10 anos).

Acham que os pais estão disponiveis para ajudar, são pessoas em que a gente pode confiar (Ricardo, 12 anos).

Criança tem pai e mãe e irmão. Ele (irmão) me irrita, não é muito legal, ele fica me enchendo (Helena, 7 anos).

Cabe salientar a fala de Augusto, pois é a única que menciona o choro como possibilidade comunicativa e amplia nossa compreensão a respeito do seu sentido para as crianças. Elas choram ao não conseguirem nomear suas emoções por meio de palavras capazes de simbolizar o que estão sentindo e, o fazem através das lágrimas que brotam de seus corpos. 0 choro, nessa perspectiva, torna-se uma forma de comunicação para as crianças. Alguns adul- tos tentam calá-lo, sem ao menos tentar compreender o que elas desejam expressar e, para isso, reproduzem expressões partilhadas culturalmente como: "Não chore, logo vai passar", "você já está grande para chorar" ou "homem não chora", as quais denotam que parar de chorar faz parte do se tornar adulto, principalmente no universo masculino. No entanto, os adultos, mesmo os homens, também choram e fazem isso quando suas emoções afetam seus corpos que submetidos pela dor, pela raiva pelo medo ou por qualquer outro sentimento, produzem lágrimas. As crianças sinalizam que há outras formas expressivas que necessitam ser consideradas e, por essa razão, buscam espaços para que sejam reconhecidas, posto que fazem parte do processo de construção de sua humanidade.

\section{Considerações possíveis}

Iniciamos o texto perguntando: "O que é ser criança?". Em busca de respostas possiveis, percorremos um longo caminho que nos aproximou da legislação, da tradição, do pensamento científico e, sobretudo, do que as crianças têm a dizer sobre a pergunta que direcionou este percurso.

De forma leve e verdadeira, sinalizam o brincar como parte constituinte de uma criança histórica e culturalmente encarnada, assumindo uma centralidade a partir da qual derivavam todas as relações que estabeleciam com sua cultura, seus pares, com os adultos e com os espaços. Por meio do brincar, são capazes de criar mundos que se mesclam aos existentes, propondo o novo.

Nessa perspectiva abrem um campo de negociação com os adultos, no qual foi possivel identificar tensões que envolviam uma disputa pelo reconhecimento e legitimação de suas ações e de seus espaços de atuação. Na escola, o brincar mostrou-se apartado das situa- 
ções que envolviam a aprendizagem formal e o desempenho do ofício de aluno, ficando relegado aos períodos de recreio; e aos passados em casa, permitido desde que se respeitasse os ambientes.

Quanto aos espaços, cabe salientar que apenas a escola e a casa foram mencionados, silenciando alguns que poderiam ser lembrados, tais como cinema, teatro, parques, praças, dentre outros tantos. Considerando o período de isolamento social, imaginamos que, talvez, em outras condições as respostas pudessem ser diferentes, o que abre espaço para uma questão que necessita ser melhor investigada acerca dos espaços que essas crianças reconhecem como seus, destinados ao convívio social.

Incluíram a família em suas narrativas, ora se referem à família como espaço acolhedor que simboliza um porto seguro, ora mostram que viver em família implica conviver com tensões desencadeadas por relacionamentos que implicam desentendimentos.

Outro elemento de destaque refere-se aos sentidos atribuídos aos códigos sociais e à própria imagem que possuíam sobre si. Embora reconhecessem os direitos e as interdições impostas às crianças, verificamos que ao se definirem como tal, passavam a utilizar adjetivos como: "baixinho", “louco", “agitado", dentre outros, que, nem sempre, convergiam para a ideia de uma criança potente, que possui o status legal de um sujeito de direitos, denunciando que apesar de sua potência criativa e inovadora se revelar mediante a sua capacidade de criar suas próprias culturas, há ainda um longo caminho a ser percorrido para que as próprias crianças e também os adultos as vejam como sujeitos de direitos.

Tais achados reforçam a necessidade de maior participação das crianças em temas que lhes dizem respeito, uma vez que permitem descortinar as estruturas que organizam seus espaços e orientam suas práticas, podendo potencializar a vitalidade e a capacidade de inovação que carregam em si. A luta pelo reconhecimento do brincar e de suas diferentes linguagens perpassa, não apenas um aspecto formal da organização da vida das crianças, mas apresenta-se como uma possibilidade de reconhecimento da legitimidade de suas demandas. É uma busca que visa à valorização de seus modos de existir e de constituição de suas subjetividades. A pesquisa com crianças, nessa perspectiva, se situa, segundo Gullestad (2005), como uma das formas pelas quais o texto frio da lei toma corpo e se configura como espaço onde a criança pode ter contemplada a potência de suas linguagens.

\section{Referências}

ANDRADE, Daniela de Barros da Silva Freire. 0 potencial narrativo dos lugares destinados às crianças: incursões do grupo de pesquisa em psicologia da infância GPPIN. Fractal: Revista de Psicologia, Rio de Janeiro, v. 27, n. 1, p. 16-21, abr. 2015. Disponível em: https://periodicos.uff.br/fractal/article/ view/4992. Acesso em: 10 maio 2020.

ARIÈS, Philippe. História social da criança e da família. 2 ed. Rio de Janeiro: LTC, 1981.

BARBOSA, Maria Carmen Silveira. Culturas escolares, culturas de infância e culturas familiares: as socializações e a escolarização no entretecer destas culturas. Educação e Sociedade, Campinas, vol. 28, n. 100, p. 1059-1083, out. 2007. Edição especial. Disponivel em: https://www.scielo.br/pdf/es/v28n100/ a2028100.pdf. Acesso em: 10 maio 2020.

BYINGTON, Carlos Amadeu. A construção amorosa do saber: o fundamento e a finalidade da pedagogia simbólica junguiana. São Paulo: Linear, 2011.

BRASIL. Lei n. 8.069, de 13 de julho de 1990. Dispõe sobre o Estatuto da Criança e do Adolescente e dá outras providências. Diário Oficial da União. Brasília, DF, 16 jul. 1990.

BRASIL. Lei n. 9.394, 20 de dezembro de 1996. Esta- 
belece as diretrizes e bases para a educação nacional. Diário Oficial da União. Brasília, DF, 23 dez. 1996.

BROUGÈRE, Gilles. Brinquedo e cultura. São Paulo: Cortez, 2001.

CHARLOT, Bernard. A mistificação pedagógica: realidades sociais e processos ideológicos na teoria da realidade. São Paulo: Cortez Editora, 2013.

CHEVALIER, Jean; GHEEBRANT, Alain. Dicionário de símbolos. Rio de Janeiro: José Olympio, 1998.

CORSARO, William A. Sociologia da Infância. Porto Alegre: Artmed, 2011.

DELORY-MOMBGERGER, Christine. Abordagens metodológicas na pesquisa biográfica. Revista Brasileira de Educação. v. 17, n. 51, p. 523-536, set.- dez. 2012. Disponivel em: https://www.scielo.br/scielo. php?pid=S1413-24782012000300002\&script=sci_arttext\&tlng=pt. Acesso em: 10 maio 2020.

DEMARTINI, Zeila de Brito Fabri. Infância, pesquisa e relatos orais. In: FARIA, Ana Lucia Goulart de; DEMARTINI, Zeila de Brito Fabri; PRADO, Patricia Dias. (org.). Por uma cultura da infância: metodologia de pesquisa com crianças. Campinas: Autores Associados, 2002. p. 1-17.

FOUREZ, Gérard. Educar: docentes, alunos, escolas, éticas, sociedades. Aparecia SP: Ideias \& Letras, 2008.

FURLANETTO Ecleide Cunico; HERRERA, Marli Aparecida; MEDEIROS, Aline de Souza. As crianças narram e desnaturalizam experiências vividas nas escolas de infância. In: (Orgs.) PASSEGGI, Maria da Conceição; LANI-BAYLE, Martine; FURLANETTO, Ecleide Cunico; ROCHA, Simone Maria da. Pesquisa auto (biográfica) em educação: infâncias e adolescências em espaços escolares e não-escolares. [recurso eletrônico Natal, RN: EDUFRN, 2018. p. 261-288].

FREITAS, Marcos Cezar de (org.). História social da infância no Brasil. São Paulo: Cortez, 2016.

GENEBRA. Geneva Declaration of the Rights of the Child. Adotada em 26 de setembro de 1924 pela Liga das Nações. O. J. Spec. Supp. 21, at, 1924. Disponível em: http://hrlibrary.umn.edu/instree/childrights. html. Acesso em: 30 mai. 2020.
GULLESTAD, Marianne. Infâncias imaginadas: construções do eu e da sociedade nas histórias de vida. Revista Educação e Sociedade, v. 26, n. 91, p. 509534, mai.- ago. 2005. Disponivel em: https://www. scielo.br/pdf/es/v26n91/a11v2691.pdf. Acesso em: 10 maio 2020.

HONNETH, Axel. Luta por reconhecimento: a gramática moral dos conflitos sociais. São Paulo: Editora 34, 2009.

JODELET, Denise. A cidade e a memória, In: DEL RIO, Vicente; DUARTE, Cristiane Rose; RHEINGANTZ, Paulo Afonso. (Org.). Projeto do lugar: colaboração entre Psicologia, Arquitetura e Urbanismo. Rio de Janeiro: Contra Capa Livraria, 2002. p. 31-43.

JOVCHELOVITCH, Sandra. Os contextos do saber: representações, comunidade e cultura. Petrópolis, RJ: vozes, 2011.

JOVCHELOVITCH, Sandra; BAUER, Martin W. Entrevista narrativa. In: BAUER, Martin W.; GASKEL, George. Pesquisa qualitativa com texto, imagem e som: um manual prático. Petrópolis, RJ: Vozes, 2002. p. 90-113.

JUNG, Carl Gustav. Os arquétipos e o inconsciente coletivo. Petrópolis: Vozes, 2000.

KISHIMOTO, Tizuko Morchida. 0 brincar e suas teorias. São Paulo: Cengage, 2011 .

KISHIMOTO, Tizuko Morchida. (Org). Jogo, brinquedo, brincadeira e a educação. São Paulo: Cortez, 2011b.

KRAMER, Sonia. Autoria e autorização: questões éticas na pesquisa com crianças. Cadernos de Pesquisa, São Paulo, n. 116, p. 41-59, jul. 2002. Disponivel em: https://www.scielo.br/scielo.php?pi$d=$ S0100-15742002000200003\&script=sci_abstrac t\&tlng=pt. Acesso em: 10 maio 2020.

MARKOVÁ, Ivana. Mente dialógica: senso comum e ética. Cambridge: Cambridge University Press; São Paulo: Fundação Carlos Chagas; Curitiba: PUCPress, 2017.

MASSCHELEIN, Jan; SIMONS, Maarten. Em defesa da escola: uma questão pública. Belo Horizonte: Autêntica, 2013. 
MORIN, Edgar. Meus demônios. Rio de Janeiro: Bertrand Brasil, 1997.

NIETZSCHE, Friedrich. Assim falou Zaratustra. São Paulo: Hemus, 1979.

PASSEGGI, Maria da Conceição; et al. Narrativas de crianças sobre as escolas da infância: cenários e desafios da pesquisa (auto)biográfica. Educação, Santa Maria, v. 39, n. 1, p. 85-104, jan./abr. 2014. Disponivel em: https://periodicos.ufsm.br/reveducacao/article/view/11345 Acesso em: 10 maio 2020.

PASSEGGI, Maria da Conceição; NASCIMENTO, Gilcilene; RODRIGUES, Senadaht. Narrativas de crianças sobre a escola: desafios das análises. Revista Lusófona de Educação, n. 40, p. 155-169, 2018. Disponível em: https:// revistas.ulusofona.pt/index.php/rleducacao/article/view/6440. Acesso em: 10 maio 2020.

PASSOS, Maria Consuêlo. A constituição dos laços na família em tempos de individualismo. Mental, Barbacena, v. 5, n. 9, p. 117-130, nov. 2007. Disponivel em: http://pepsic.bvsalud.org/scielo.php?script=sci_arttext\&pid=S1679-44272007000200008. Acesso em: 10 maio 2020.

PÉREZ GÓMEZ, Angel I. La cultura escolar em la sociedade neoliberal. Madrid: Morata, 2004.

PIERI, Paolo Francesco. Dicionário junguiano. São Paulo: Paulus, 2002.

QVORTRUP, Jens. Crescer na Europa: horizontes atuais dos estudos sobre infância e juventude. CEDIC (Centro de Documentação e Informação sobre a Criança). Universidade do Minho, 1999.

QVORTRUP, Jens. A volta do papel das crianças no contrato geracional. Revista Brasileira de Educação, v. 16, n. 47, p. 323-332, mai. - ago. 2011. Dispo- nível em: https://www.scielo.br/pdf/rbedu/v16n47/ v16n47a04.pdf. Acesso em: 10 maio 2020.

QVORTRUP, Jens. Visibilidade das crianças e da infância. Linhas Críticas, Brasília, DF, v. 20, n. 41, p. 2342, jan.-abr. 2014. Disponivel em: https://periodicos. unb.br/index.php/linhascriticas/article/view/4250. Acesso em: 10 maio 2020.

SANTOS, Santa Marli Pires dos. Brinquedoteca: o lúdico em diferentes contextos. Petrópolis, RJ: Vozes, 2011.

SARMENTO, Manuel Jacinto. A reinvenção do oficio de criança e de aluno. Atos de Pesquisa em Educação. v. 6, n. 3, p. 581 - 602, set./dez. 2011. Disponivel em: https://proxy.furb.br/ojs/index.php/atosdepesquisa/article/view/2819. Acesso em: 10 maio 2020.

SARMENTO, Manuel Jacinto. As culturas da infância nas encruzilhadas da 2 a modernidade. In: CERISARA, Ana Beatriz; SARMENTO, Manuel Jacinto. Crianças e miúdos: perspectivas sócio-pedagógicas da infância e educação. Porto: Asa, 2004. p. 9-34.

SKLIAR, Carlos. Desobedecer a linguagem: educar. Belo Horizonte: Autêntica, 2014.

VON FRANZ, Marie-Louise. A individuação nos contos de fada. São Paulo: Paulinas, 1985.

WINNICOTT, Donald W. A família e desenvolvimento individual. São Paulo: Martins Fontes, 2011.

WINNICOTT, Donald W. 0 brincar e a realidade, Rio de janeiro: Imago,1975.

Recebido em: 20/06/2020 Revisado em: 25/08/2020 Aprovado em: 02/09/2020

Ecleide Cunico Furlanetto é doutora em Educação (Psicologia da Educação) pela Pontifícia Universidade Católica de São Paulo (PUC-SP) e pós-doutora pela Universidade de Barcelona. Professora e vice-coordenadora do Programa de pós-graduação em Educação da Universidade Cidade de São Paulo (Unicid). Membro do grupo de pesquisa Narrativas, Aprendizagem e Formação (NARRAR).E-mail: ecleide@terra.com.br

Karina Alves Biasoli é doutora em Educação (Psicologia da Educação), pela Pontifícia Universidade Católica de São Paulo (PUC-SP). Pós-doutoranda em Educação pela Universidade Cidade de São Paulo (Unicid). Membro do grupo de pesquisa Narrativas, Aprendizagem e Formação (NARRAR).E-mail: karinabiasoli@yahoo.com.br 